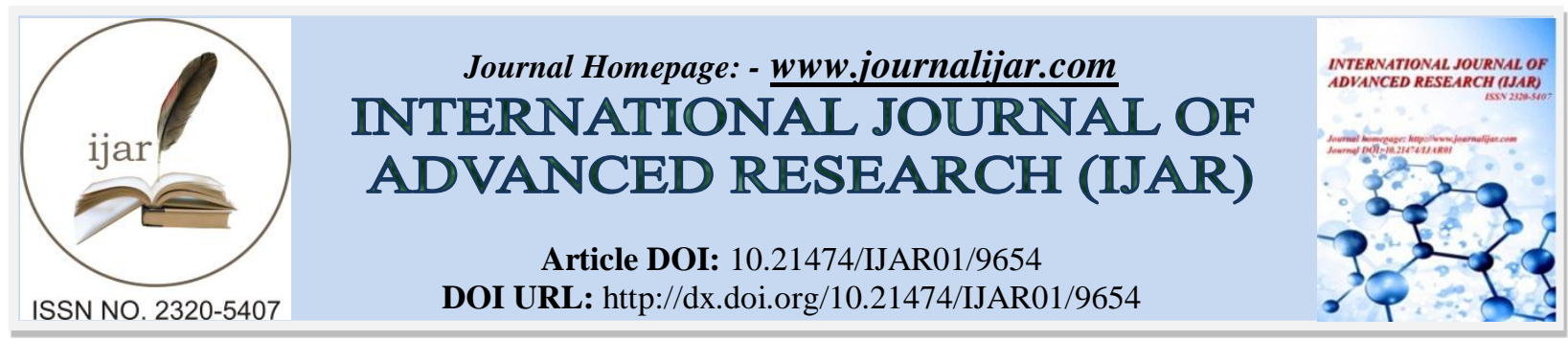

RESEARCH ARTICLE

\title{
IS HEPATITIS C LIKE A HOT KNIFE THROUGH BUTTER? (A SILENT KILLER).
}

\author{
Raghavendra Rao M.V. ${ }^{1}$,Sateesh Arja ${ }^{2}$, S P Pallavi ${ }^{1}$, Kumar Ponnusamy ${ }^{2}$, Mahendra Kumar Verma ${ }^{3}$, Reshma $^{2}$ \\ Fatteh $^{2}$ Jattavathu.Madhavi $^{3}$ and Sirisha Bala ${ }^{2}$. \\ 1. Apollo Institute of Medical Science and Research Institute, Jubilee Hills, Hyderabad, India. \\ 2. Avalon University School of Medicine, Curacao, Central America. \\ 3. Acharya Nagarjuna University,Nagarjuna Nagar,Guntur, Andhra Pradesh,,India.
}

\section{Manuscript Info}

Manuscript History

Received: 04 July 2019

Final Accepted: 06 August 2019

Published: September 2019

Key words:-

Enzyme-linked

(ELISA), INF-alfa

(INFAR), Magnetic

elastography, SVR (Sustained virologic response).

\section{Abstract}

Hepatitis $C$ virus belongs to the flavi virus family. Hepatitis $C$ virus is known as Non-A and Non-B hepatitis. It exists in six genotypes with different worldwide distribution. It is a curable disease.HCV is the common cause of transfusion and liver transplant-associated hepatitis. It can also be considered as STD and can be transmitted at birth from an HCV infected mother. Acute disease is usually mild but $70 \%$ of those infected develop chronic disease. A high percentage of individuals had an asymptomatic disease that leads to cirrhosis and liver failure. Hence each year, the percutaneous injury resulted in around $16,000 \mathrm{HCV}$ and caused about 8000 deaths in the USA. Clinically acute infection with HCV is milder than infection with HBV (1).

Copy Right, IJAR, 2019,. All rights reserved.

\section{Introduction:-}

$\mathrm{HCV}$ is a single stranded RNA virus that belongs to the family Flaviviridae and genus hepacivirus. As estimated 130 to 170 million people world wide are chronically infected with $\mathrm{HCV}$, with 3-4 million new infections reported every year and majority of these individuals have low and middle income countries (LMCs)(2)

Worldwide, chronic infection with the hepatitis-C virus is the second most common cause of HCC accounting for $20 \%$ of all $\mathrm{HCC}(3)$

Nearly half million HCV infected people die every year annually due to absence of accessible and effective diagnostic and treatment facilities in most of these LMICs (4)

Liver is the primary organ affected by chronic hepatitis $\mathrm{C}$ virus (HCV), a broad clinical the spectrum of extra hepatic complications and diseases are associated with this viral infection(5)

WHO mandates acceleration of HCV screening and diagnosis to meet its global goal of eradication of HCV by 2030(6)

Moreover, outbreaks of hepatitis C among HIV positive homosexual men have been reported2000 (7)

Prevalence of cirrhosis and mortality seems to be lower in patients with effective antiviral treatment $(8,9)$

Corresponding Author:-Raghavendra Rao M.V..

Address:-Apollo Institute of Medical Science and Research Institute, Jubilee Hills, Hyderabad, India. 
High incidence of acute hepatitis-C virus infections in Human immunodeficiency virus (HIV) positive men who have sex with men (MSM) has been observed in many European countries, as well as Australia and USA $(10,11)$

Several recent studies described an incidence of acute HCV infection in Dutch HIV positive MSM of 11/1000 person year of follow up (PYFU)(12)

The Type 1 interferon exerts their action through binding to a specific cell surface receptor complex known as the INF-alfa receptor(INFAR) that consists of IFNAR1 andIFNAR2 chains. The two commercially available IFNs in widespread usage for the treatment of hepatitis $\mathrm{C}$ are INF-alfa and INF alfa2b (13)

This is an extremely high incidence in a country where the overall $\mathrm{HCV}$ prevalence is estimated at $0.2 \%$.It is described a comparably high incidence of HCV infection among HIV positive MSM in several other European countries(14)

More than 170 million people are chronic carriers of $\mathrm{HCV}$ and at high risk of developing liver cirrhosis and/or hepatocellular carcinoma (HCC). Three to $4 \%$ of chronically infected individuals develop fatal HCC. Currently, HCC caused by HCV infection is considered an indication for liver transplantation (15)

The faster fibrosis progression in HIV/HCV co-infection patients in particular with declining CD4 cell counts has also prompted many guidelines to prioritize HCV therapy in HCV co-infected subjects (16)

Studies on Chimpanzees reveal, two days after infection, HCV RNA levels rise, followed by a plateau within two days, concomitant with the induction of intrahepatic type 1 INF $(17,18)$

Fibrosis is the principal complication of chronic hepatitis C, and it is estimated that $20 \%$ of patients develop cirrhosis over a period of 10,20 or 30 years

$(19,20)$

\section{History}

The first association of blood transfusion with hepatitis was in 1943 (21) Willow brook clarified the transmissibility of a hepatitis agent from human plasma (22) The virus, initially called non-A, non-B hepatitis (NANBH). Inoculation of chimpanzees with blood components from humans having both acute and chronic NANBH resulted in characteristic elevations of transaminases, providing a valuable animal model for NANBH. By the mid-1980s, physicochemical studies of infectious inocula had revealed that the NANBH agent was small, enveloped virus (23) HBV and HCV virus co-infection mostly seen in South East Asia and Mediterranean countries. The two viruses inhibit each other mutually at the same time. Generally one plays a dominant role over the other. Generally HBV dominates HCV. Mostly, HCV strongly suppresses the HBV replication on co-infected patients.

Scientists in the United States and Japan finally identified this major cause of parent rally transmitted hepatitis in 1989 and designated it as the $\mathrm{HCV}(24,25)$

A vaccine against hepatitis $C$ is a remote possibility until recently. However, the outlook for hepatitis $C$ vaccine has improved with advances in our understanding of the correlates of spontaneous immunity $(26,27)$. The discovery led to significant improvements in diagnosis and improved antiviral treatment (28) The role of antiviral therapy in acute hepatitis $\mathrm{C}$ is unclear. Acute infections are usually asymptomatic and found incidentally, such as needle stick injuries in health care workers. It is not clear what \% of these cases becomes chronic. Some studies have shown that early treatment with INF or combination therapy decrease the chronicity rate in patients with acute hepatitis C (29) The current standard of care for hepatitis $\mathrm{C}$ is pegylated interferon used in combination with ribavirin. Each genotype responds differently to a treatment.(30) The discovery and cloning of HCV have led to a greater understanding of its relationship to acute and chronic hepatitis, cirrhosis, primary liver cancer, and extra hepatic conditions including essential cryoglobulinemia, glomerulonephritis, and serum autoantibody positivity(31)

Researchers discovered the hepatitis C virus in the late 1980s, and they were first able to grow the virus as a cell culture in 2005. Before this, researchers could not study how medications or vaccines might change the virus. 


\section{Significant Gap In Research}

The current strategy targets the high prevalence population with advanced liver disease at near term risk of HCV associate mortality and cost effective. But it misses younger more recently infected persons. Risk based strategies are currently used to identify persons with HCV not in birth cohort. Risk based testing in addition to birth cohort testing is more effective than either strategy alone (32)

$\mathrm{HCV}$ c protein has been implicated in numerous cellular pathways, including altered signaling, transcriptional control apoptosis and cellular transformation (33)

Sub genomic replications were developed in 1999 and proved to be the best broadly useful system for studying HCV RNA replication cell culture (34)

In 2005, production of authentic HCV in cell culture (HCVcc) was achieved the first time. (35)

Needle exchange programs are a vital tool in preventing HCV infection among young persons who inject drugs Massachusetts is experiencing a troubling with an especially sharp rise in the last 2 years of opioid related deaths (36)

\section{Where research go next?}

There is no vaccination or prophylaxis against hepatitis C So early identification and treatment of infected individuals is required and has been shown to reduce the risk of developing chronic infection. Increased risk of needle injuries is identified and corrected. The therapeutic vaccine would also be an invaluable adjunct to current treatment options for HCV. Compared with hepatitis C virus single infection, HBV/HCV confected patients tend to have a more severe liver injury, a higher probability of cirrhosis, and hepatocellular carcinoma For those with HCV and low level of HBV viremia, treatment with PEG-INF and ribavirin can be as effective as in HCV mono-infection. To days' gold-standard treatment for HCV consists of pegylated interferon and ribavirin. This has been a remarkable advance in the treatment of HCV and may result in the permanent eradication of the virus in infected people. Nevertheless, it is currently expensive, has extensively side effect and is often ineffective. Several medications, now available to treat hepatitis $\mathrm{C}$. While medication assistance is available, and some insurance companies pay for treatment, preventing the disease would be significantly more cost-effective (37)

)In US and Europe nearly 34\% infected persons are co-infected with both HIV and HCV. In chronic infection, HCV RNA levels are higher in HIV co-infected patients, the efficacy of anti-HCV therapy is reduced and the incidence of cirrhosis and $\mathrm{HCC}$ is higher.

\section{Major Advances And Discoveries}

Laboratory diagnosis is carried out by ELISA. False results can occur in ELISA, a recombinant immunoblot assay (RIBA) should be performed as a confirmatory test. If the results of RIBA are positive a polymerase chain reactionbased test that detects the presence of viral RNA(Viral load)in serum should be performed to determine whether active disease exists. Reduction of the viral load in patients with hepatitis $\mathrm{C}$ is used to monitor the success of drug therapy. $85 \%$ of cases of acute hepatitis $\mathrm{C}$ may develop chronic hepatitis. Clinically it can't be differentiated from chronic hepatitis. SGPT level is normal in about $40 \%$ cases. It can be tested by enzyme immunoassay.(EIA)In suspected cases where EIA is negative HCV RNA can be detected by PCR. In about $20 \%$ of cases, cirrhosis develops after 20 years particularly in men who acquire the infection after 40 years and alcoholics and immunosuppressant(38)

\section{Screening}

Screening should be done who injected or inhaled illicit drugs, liver function test results with higher results, Babies born to mothers with hepatitis $\mathrm{C}$, Health care and emergency workers who have been exposed to blood or accidental needle sticks, People who undergone long-term hem dialysis treatments, blood transfusions or organ transplants, people with HIV infection and born from 1945 to 1965.

\section{Diagnosis}

A number of immunoassays have been developed to detect anti-HCV IgG in serum or plasma specimens. Virology diagnosis of $\mathrm{HCV}$ infection is based on two categories of laboratory tests, namely serologic assays detecting specific antibody to $\mathrm{HCV}$ (anti-HCV) (indirect tests) and assays that can detect, quantify, or characterize the components of 
HCV viral particles, such as HCV RNA and core antigen (direct tests). Direct and indirect virology tests play a key role in the diagnosis of infection, therapeutic decision-making, and assessment of virology response to therapy (39)

Recombinant immunoblot assays (RIBA) were used in the past as supplemental assays to confirm serological reactivity by ELISA, but are now clinically obsolete with the availability of molecular tests. Confirmation of serological reactive tests may be done by a nucleic acid test (NAT) for detection of HCV RNA. Recent studies have also suggested that higher the anti-HCV antibody titer in the patient's serum; more are the chances of it being true positive than false positive (40)

\section{Treatment}

Ribavirin (Copegus and Rebetol) is one of the older drugs that doctors prescribe for hepatitis infections.Daclatasvir is one of the newer drugs for hepatitis C.Treatment for HCV infection is available. The role of treatment in acute infection is being evaluated and currently 6 months of standard therapy with interferon (IFN) in terms of absence of HCV RNA from serum is excellent and progression to chronicity is reduced. The recommended treatment for chronic HCV infection is a combination of a pegylated IFN alpha and ribavirin. The treatment duration depends on the genotype of the virus and it has two goals. The first is to achieve sustained eradication of HCV, that is, sustained virology response (SVR), which is defined as the persistent absence of HCV RNA in serum for 6 months or more after completing antiviral treatment. The second goal is to prevent progression to cirrhosis, HCC, and decompensate liver disease requiring liver transplantation(41)

New types of improved antiviral drugs were discovered. Telaprevir, boceprevir are the protease inhibitors. These are antiviral drugs.PEG-ING and ribavirin improve virological response. Polymerase inhibitors are also shown good response. Currently, Polymerase inhibitors, protease inhibitors, and ribavirin are found fit to cure hepatitis $\mathrm{C}$ infection.HCV treatments provide cure rates that are more than $90 \%$ highlighting the importance of diagnosis.Current US preventive service task force include routine 1-time testing of persons born between 19451965 " referred $t$ as the birth cohort" and targeted testing to high risk persons(42)

\section{Current Debate}

Interferon alpha therapy of acute hepatitis C-is well-established Response rate is high. Some of the serological markers in Hepatitis are platelet counts, ALT, GGT, Bilirubin, Cholesterol-The most common markers used in current assays involve measuring products of extracellular matrix synthesize or degradation and the enzyme that regulate their production and modification.In addition to liver biomarkers, the new technological advances MRI, Magnetic resonance elastography are also highly useful in the assessment of liver fibrosis.HCC remains the common cause of cancer mortality worldwide. The new antiviral agents are likely to decrease the incidence of HCC in parts of the world. Recent evidence has shown that HCV infection has a detrimental effect on patient and graft survival in patients with CKD (Chronic kidney disease)New therapies for $\mathrm{CHC}$ are now available in clinical practice. The primary route of $\mathrm{HCV}$ entry is percutaneous although per mucosal infection has also been described.(43)

The field of HIV therapeutics is rapidly advancing and it is expected that efficacious and safe directly acting antiHCV agents will revolutionize the HCV treatment. The initial use of such agents will involve their combination with peginterferon and ribavirin(44)

In 1990 and related years, the measurement of HCV RNA levels is made available.It is now widely used to tailor pigmented INF-alfa and ribavirin, treatment duration and will still be useful for that purpose when telaprevir and boceprevir are prescribed in combination with these two drugs in patients infected with HCV genotype-1.It is likely that virologic response-guided therapy will remain essential in the future, especially in an era of INF-free regiments.(45)

Currently, HCV is responsible for about 8000 deaths annually in the USA. Furthermore, HCV is the leading reason for liver transplantation in the USA. Treatment with ribavirin and pegylated polyethylene Glycerol recombination therapy can rid the virus in $50 \%$ of those infected with genotype 1 and in the $80 \%$ of those infected with genotype 2or3 (46)

All pregnant women and people born 1945-1965 have to be screened. Natural killer (NK) cells are important for maintenance of innate immune system stability and serve as a first line of defense against tumors and virus infections; they can act either directly or indirectly and are regulated via co-operation between inhibitory and 
stimulatory surface receptors. The recently reported inhibitory receptor, TIGIT, can be expressed on the NK cell surface; however, the expression level and function of TIGIT on NK cells during HIV infection is unknown. Recently, the expression and function of TIGIT in NK cells from HIV-infected individuals. Currently,it is observed that the level of TIGIT is higher on NK cells from patients infected with human immunodeficiency virus (HIV) compared with HIV-negative healthy controls. TIGIT expression is inversely correlated with CD4+ T cell counts and positively correlated with plasma viral loads (47)

\section{Challenges}

The advanced discovery of direct-acting antivirals (DAAs) is highly useful in the treatment of chronic hepatitis C infection. Direct acting antivirals are now useful in the elimination of HCV scrupulously. In spite of the recent modern drugs still, HCV threat remains challenging. No doubt the direct-acting antiviral drugs have completely changed the treatment scenarios. It is an exciting but challenging opportunity.It is estimated that nearly $40,000 \mathrm{HCV}$ related deaths occurring annually. Discoveries in the areas of molecular biology, immunology, and microbiology is required to face the challenge.

\section{Summary}

Patients who have been diagnosed with chronic infection, however often complain of fatigue or depression, and they consistently score lower than HCV negative persons in all aspects of health-related quality of life.It reverts when using antiviral therapy.A number of extrahepatic complications have been associated with hepatitis $\mathrm{C}$ infection, including cryoglobulinemia, glomerulonephritis, porphyria, cutaneous tarda, polyarteritis nodosa, Sjogren's syndrome, and lichen planus

HCC remains a common cause of cancer mortality worldwide, with a significant contribution due to chronic hepatitis $\mathrm{C}$ infection. The new direct-acting antivirals agents are likely to decrease the incidence of $\mathrm{HCC}$ in parts of the world that can afford them. The field of HCV therapeutics is rapidly advancing and it is expected that efficacious and safe direct-acting anti-HCV agents will revolutionize the HCV treatment. Nevertheless, a number of studies need to be performed with highly sensitive and accurate assays based on real-time PCR in order to establish the best use of viral kinetic monitoring.

\section{Conclusion:-}

Acute HCV infection is observed for 3-4 months after the onset of symptoms. Antiviral therapy has to be started. The main stray of treatment is the combination of INF and ribavirin. Later pegylated IFN., which consists of polyethylene glycol(48)

Reducing the spread of infection, by raising awareness, screening of blood products, Hygiene/disinfection, post, and pre-exposure prophylaxis and vaccination. Genomic screening for this the infectious agent became possible with the development of various nucleic acid amplification techniques(NAT), such as polymerase chain reaction(PCR), Ligase-chain reaction(LCR), Nucleic acid sequence based amplification(NASBA)and transcriptions(mediated amplification(TMA) techniques are now available.Recent evidence has univocally shown that HCV has a detrimental effect on the patient. Care and develop strategies in the elimination of HCV is mandatory. Identifying those people infected with HCV and to be screened. Risk group, people have to be screened one time. Drug cost is a problem in underdeveloped and even developed countries.

\section{References:-}

1. WarrenLevinson,Review of Medical Microbiology, 13 th Ed,Mc Graw Hill Edu,PP 338

2. Bennet S,Genson RN,MC Allister GE,Hutchenson et al.Detection of HCV RNA,indirect blood spot,J.Cli. Virol,2012,15;2012;54,106-9

3. Bosch FX, Ribes J, Diaz M, Cleries R Primary liver cancer; Worldwide incidence and trends Gastroenterology.2004;127 (5.suppl1)55-16

4. WHO global policy report on the preventive and control of viral hepatitis 2013,accessed on August 2014 Mayo.M.Extrahepatic manifestations of hepatitis-C- infection.Am.J Med.Sci. 2002;325;135-48

5. WHO guidelines on hepatitis B and C testing World health org,2017

6. Vogel M, Deterding K Wiegand J.et.al, initial presentation of acute hepatitis C virus(HCV)infection among HIV negative and HIV positive individual experience from 2 largeGerman networks on the study of acute HIV infection.Clin.Infect.Dis 2009,49(2);317-9, author reply 319. 
7. Benhamou Y,Di Martino V,Bochet.M,et.al, Factors affecting liver fibrosis, in human immunodeficiency virus and hepatitis $C$ virus-coinfected patients.Impact of protease inhibitor therapy.Hepatology.2001;54(2),2837.

8. Qureshi N, Kreuzberg C, Luchters G, et.al Effect of antiretroviral therapy on liver-related mortality in patients with HIV and hepatitis C virus coinfection.Lancet.2003;362 (9397);1708-13

9. Kuo G,Choo QL,Alter HJ.et.al.An assay for circulating antibodies to major etiologic virus of human non A non B hepatitisScience 1889;244;362-4

10. Wandler G,G S Poner T,Bregezer et al.Swiss HIV cohort study.A rapid evolving epidemic cli. Inf.Dis.,2012;55;1408-16

11. Ghisla V,Scherrer AU,Nicca D, Brun DL,Fehr JS,Incidence ofHCV positive and Negative men who have sex with men 2000-2016.A systemic review and meta analysis infection,2017;45:309-21

12. Feld.J, Hoffnagle JH .Mechanism of action of interferon and ribavirin in the treatment of hepatitis C Nature $2005 ; 436 ; 967-72$.

13. Van Santen Dk,Dervan Helm et al.Lack of discipline in HCV incidence among HIV positive men who have sex with men during 1990-2014.J.Hepatol.2017;67:255-62

14. Seeff LB. Natural history of chronic hepatitis C. Hepatology 2002; 36: S35-S46 [PMID: 12407575 DOI: 10.1002/ hep.1840360706] 4 Pawlotsky JM. T

15. LoRe V,Kallan MJ,Tate JP, et al.Hepatic decompensation.In anti viral treated patients Co-infected with HIV and HCV compared with HCV monitored patients,A cohort study.Ann.Intr.Med.2014;160:369-79.Bigger CB, Brasky KM, Laford RE.

16. DNA microarray analysis of chimpanzees liver during acute resolving hepatitis $\mathrm{C}$ virus infection.J.Virology.2001;75(15) 7059-66

17. Su.Al, Pezacki JP, Wodicka L et.al, Genomic analysis of the host response to hepatitis $\mathrm{C}$ virus infection.Proc.Natl.Acad Sci USA,2002;99(24);15669-74

18. Fried MW, Shiffman ML, Reddy KR, Smith C, Marinos G, Goncales Jr.Fl,et.alCombination of peginterferon alfa-2a(40kd) plus ribavirin in patients with chronic hepatitis C virus infection.N.Engl.J.Med.2002;347;975-82

19. Mann MP, Mc Hutchinson G,Gordon SC,Rustgi VK, Shiffman ML, Reindollar R,et.al, Peginterferonalfa $2 b$ plus ribavirin compared with interferon alfa $2 b$ plus ribavirin for initial treatment of chronic hepatitis C ;a randomized trial.Lancet.2001;358;958-65.

20. Lurman A.Eine icterus epidemic.Berlin Klin Wochenschr.1885;22;2

21. Krugman.S, FilesJP.Hammond J.

22. infectious hepatitis; evidence for two distinctive clinical, epidemiological, and immunological types of infection.JAMA 1967;200;365-73

23. Boyer, JL (2001). Liver cirrhosis and its development: proceedings of the Falk Symposium 115. Springer. pp. 344. ISBN 978-0-7923-8760-2

24. Bradly DW,McCausland KA,CookEH,et.al.Post-transfusion non-A, Non-B hepatitis in chimpanzees; physicochemical evidence that the tubule-forming agent is a small, enveloped virus. Gastroenterology,1985;88;773-9.

25. Choo QL,Kuo G,Weiner AJ,et.al.Isolation of a CDNA clone derived from a blood-borne Non-A,non-B viral hepatitis genome.Science. 1989;244;;359-62

26. Ferraric,New perspectives for T cell based HCV vaccines J.Hepatol.2006,45;163-165

27. Folgori A,Caponi S, Ruggeri L,et al.A T-Cell HCV vaccine eliciting effective immunity agaist heterologous virus challenge in Chimpanzees.Nat.Med.2006;12;190-197

28. "Hepatitis C". The Lancet. 385 (9973): 1124-1135. doi:10.1016/S0140-6736(14)62401-6. ISSN 0140-6736. PMC 4878852. PMID 25687730

29. Peter R.McNally,GI/Liver secretes Plus, 4 th Edition,2010

30. Geofferey Dusheiho,Hepatic C ,chapter 20,Sherlock's disease of liver and biliary system.Edited by James S,Dooly,Anna SF et al.,2011 Blackwell Publishing Ltd,

31. Sherlock S,Hepatitis C Virus;A historical prospectiveePUBMED-NCBI.Dig.Dis.Sci.1996,Dec;41 (12 Suppl);3S-5S ;HJ,32

32. Mahajan R,Lie Sj,Klevens RM,Holmberg SD,Indications for testing among reported cases of HCV infection from enhanced hepatitis.Surveillence sites in the USA 2004-2010.Am.J.Public Health 2013;103:1445-9

33. Mc Lanchlan J.Properties of the hepatitis $\mathrm{C}$ virus core protein.A structural protein modulates cellular processes.J.Virol.Properties of the hepatitis $\mathrm{C}$ virus core proteins.A structural protein modulates cellular processes.J.Virol.Hept.;2007(1);2-14. 
34. Lohmann V,Korner F,Koch JO, et al.Replication of sub genomic hepatitis C virus RNAs in hepato celllines.Science 1999;285(5224);110-113

35. Wakita T,Pietschmann T,Keto T et al.Production of infectious hepatitis $\mathrm{C}$ virus in tissue culture from a cloned viral genome.Nat.NMed. 2005 11(7);791-796

36. Massachutts,Dept of public health.The Opioid Epidemic.Available at htpp//www.mass.gov/chapter 55.Accessed 2017

37. Rachel Nall, RN MSN, Is there a vaccine for hepatitis C? Wed 31 October 2018, Newsletter Medical News Today

38. PC Das and PK Das,Textbook of Medicine,Current books international 60,Lenin Saranee,Kolkatta,5 Th Edition.

39. Ekta Gupta, Meenu Bajpai, and Aashish Choudhary, Hepatitis C virus: Screening, diagnosis, and interpretation of laboratory assays, Asian J Transfus Sci. 2014 Jan-Jun; 8(1): 19-25.

40. Ekta Gupta, Meenu Bajpai, and Aashish Choudhary, Hepatitis C virus: Screening, diagnosis, and interpretation of laboratory assays, Asian J Transfus Sci. 2014 Jan-Jun; 8(1): 19-25.

41. Dow BC, Buchanan I, Munro H, Follet EA, Davidson F, Presscot LE, et al. Relevance of RIBA-3 supplementary test to HCV PCR positivity and genotypes for HCV confirmation of blood blood donors. J Med Virol. 1996;49:132-6)

42. Moyer VA.US preventive services task force screening for hepatitis $\mathrm{C}$ virus infection in adults.US preventive services task force recommendation statement.Ann.Intern.Med ,2013;159:349-57

43. McHutchison JG, Manus MP, Muir AJ, et al.Telaprivir for previously treated chronic HCV infection.New Eng.J.Medicine,;2010;362(14);1292-303

44. Kwo PY, Lewis EJ, McCone J et al.Efficacy of Boceprevir, an NS3 protease inhibitor, in combination with peginterferon alfa-2b and ribavirin in treatment-naive patients with genotype- 1 hepatitis $\mathrm{C}$ interferon(SPRINT1); An open-label, randomized,4multicenter phase-2 trial.Lancet;2010;376(9742);705-16.

45. Sene D,Limal N,Cacoub P,HCV associated extra hepatic manifestations a review.Metab Brain.Dis.2004;19,357-381

46. Cacoup P,Poynard T,Gillani P,et al. Extrahepatic manifestations of chronic hepatitis C MULTIVIRIC GroupMultidepartment Virus C ,Artritis.Rhem 1999;42;2204-12

47. Xiaowan Yin, 1,2,3, $\uparrow$ Tingting Liu, $1,4, \dagger$ Zhuo Wang, $1,5, \uparrow$ Meichen Ma, Expression of the Inhibitory Receptor TIGIT Is Up-Regulated Specifically on NK Cells With CD226 Activating Receptor From HIV-Infected Individuals, Front Immunol. 2018; 9: 2341.

48. Richard L.Kradin,Diagnostic pathology of infectious disease,2010,Saunders,Elsevier publications. 